\title{
Levels of Job Satisfaction amongst Malaysian Academic Staff
}

\author{
Fauziah Noordin \\ Faculty of Business Management, Universiti Teknologi MARA \\ 40450 Shah Alam, Selangor, Malaysia \\ Tel: 60-3-5544-2710 E-mail: fauziah716@salam.uitm.edu.my
}

Kamaruzaman Jusoff (Corresponding author)

Faculty of Forestry, Universiti Putra Malaysia

Serdang 43400 Selangor. Malaysia

Tel: 60-3-8946-7176 E-mail: kjusoff@yahoo.com

\begin{abstract}
A study of job satisfaction of academic staff of a public university in Malaysia used the 7-item general satisfaction scale in a survey to determine the level of job satisfaction of the academic staff. The results indicated that overall the academic staff of the university has a moderate level of job satisfaction. In addition, current status, marital status, age and salary appear to have significant impact on the respondents' level of job satisfaction. Implications on the study's findings to the management of the university are also discussed.
\end{abstract}

Keywords: Job, Academia, Satisfaction, Education, Public university

\section{Introduction}

Education is one of the most important institutional organisation of a nation. It oversees issues on national agenda. Its effective running depends firmly on its coordination in the direction of societal expectation. Successful educational programs lie on the important contributions of effort, involvement, and most importantly on the overall teacher (academic staff) professionalisation. Academic staff job satisfaction, commitment, and retention are crucial to effective schools (academic institutions). A positive and healthy university climate translates into increased academic staff job satisfaction. A healthy university climate will not only increase the job satisfaction of academic staff but it will at the same time improve the learning environment and increase the productivity of the university. In addition, it becomes significant to job satisfaction because commonly held visions and beliefs, coupled with a positive environment, carry with them energy for success.

The concept of general satisfaction is defined as the extent to which a worker feels positively or negatively about his or her job (Locke, 1976; Odom, Boxx, and Dunn, 1990). It refers to employees satisfaction with the general aspects of work situation such as pay, supervision, the firm as a whole, the job itself, fellow employees and prospects of advancement. Academic staff job satisfaction is a predictor of academic staff retention which has an effect on school effectiveness. Academic staff job satisfaction studies, nevertheless, reveal wide ranging differences in determining factors contributing to job satisfaction. Academic staff job satisfaction influences job performance, motivation, morale, attrition, and ultimately students' performance. Hall, Pearson, and Carroll (1992) in their study on the area found that teachers (academic staff) who plan to leave the teaching profession can be distinguished from those who plan to stay by the pattern of their work related attitudes, perceptions, and reactions. Borg and Riding's (1991) study on primary teachers reveal among others that job satisfaction and stress are related. Other researchers found that effective teachers place significant emphasis on student-relationships (Gay, 1995; Laden and Billings, 1994). Heller, Rex, and Cline (1992) reported that variance in teacher satisfaction can be accounted for by satisfaction in meeting students' achievement. Ability to interact with colleagues and academic staff, was also cited as the most valued form of professional stimulation (Yee, 1990). Further research on this area also reveals that support and interaction have some influence on satisfaction and retention among teachers (Boland and Selby, 1980; Theobald, 1989). In their investigation, Popkewitz and Myrdal (1991) found that teacher collaboration leads to increased feelings of teacher effectiveness and 
satisfaction.

The job expectations of a university's academic staff have shifted in recent years and seem to be growing exponentially leading to a combination of increased job related stress for the academic staff, and decreasing levels of morale and job satisfaction. Research suggested that academic staff's job satisfaction have significant impact on the job performance of the academic staff and also the academic performance of their students. Universities and academic staff need to work together to provide an atmosphere that is conducive to the education process. Academic staff attitudes are affected in part by workplace conditions such as a positive and safe work environment, a supportive administration, career progression, salary, work teams, peers, and the job itself. In addition, it is also important to academic staff, and equally connected to job satisfaction has been the need for autonomy. When decisions effecting the work environment, or revolving around university improvement are being discussed, having one opinion solicited and feeling that some value is placed on that opinion provides academic staff with some ownership in the resulting decision, and along with it a desire to help make the decision a success. On the other hand, when universities make these decisions and it is clear that the academic staff opinions are neither needed nor wanted, or if there is no value placed on them, the academic staff would feel degraded and demoralized and there is subsequently no motivation to support the decision (Briggs and Richardson, 1992). This is an indication of the presence of job dissatisfaction and these may lead to negative consequences such as low productivity, voluntary turnover (among high performers), voluntary absenteeism, tardiness, apathy, low job performance, etc. The bottom line is it may lead to a lose-lose situation which is detrimental to the health of any university.

Based on the discussion above two research questions have been formulated namely, what is the level of general satisfaction of academic staff of the university and what are the individual differences that could explain the variance in the academic staff's general satisfaction?

\section{Methodology}

All faculties, academic centers, and branch campuses of the selected public university were invited to take part in the study. A total of 10 faculties, one academic center, and ten branch campuses have consented to participate in this research project. The respondents were then chosen randomly by the participating faculties, center, and branch campuses. A total of 20 sets of the questionnaires were mailed to the participating faculties, academic center, and branch campuses. A total of 360 questionnaires were distributed and 300 completed questionnaires were returned to the researchers. The final total sample size was 237 sets of completed and usable questionnaire. This gave a response rate to $79.06 \%$.

The 7-item general satisfaction measure (Taylor and Bowers, 1972) was used in this study. Responses on the general satisfaction measure are on a 5-point disagree-agree scales, and the average of the five responses is calculated. The questionnaire for this survey was subjected to rigorous screening and had undergone several modifications. In seeking answers to the research questions, descriptive statistics of the construct was computed. Internal consistency of the scales was tested by using the Cronbach's alpha coefficient (Cronbach, 1951). To test the effect of demographic variables on the constructs used in the study, a series of two-tailed independent group t-tests and one-way between groups ANOVA with post-hoc comparison analyses were conducted.

\section{Results and discussion}

The analysis of the demographic variables indicates that there are more female than male respondents. The majority of the respondents belong to the $31-44$ years age group (53.2\%) and also in the "Married" category. Seventy-four percent of the respondents have Master as their highest education level and majority of them (52.0\%) were educated in western countries. The work demographic shows that the $50 \%$ of the respondents have worked for the university for more than 10 years and majority of them have worked for less than three organizations. Annual salary of the subjects is mostly in the "greater than RM54000" bracket. The general satisfaction measure showed acceptable level of reliability, i.e., 0.7931. Nunnaly (1967) has argued that reliability estimates of 0.50 to 0.60 are sufficient for basic research.

General satisfaction score of the respondents was at 3.82 of the 5-point Likert scale. This indicates that the respondents were moderately satisfied with their general job satisfaction. This result is not consistent with previous findings on general satisfaction (for e.g., Harrison, 1995; de Boer, 1978; Griffeth and Hom, 1987; Cole, 1979). A finding which has appeared with remarkable consistency in comparative survey research on industrial attitudes is that the levels of job satisfaction reported by Japanese are lower than in the western industrialised countries. Whether the workers studied are blue collar or white collar, whether employed in manufacturing or service industries, the Japanese respond to questionnaires and interviews that they are less content with their jobs and work lives than Americans and Europeans. For example, Azumi and McMillan (1975) survey of Japanese, British, and Swedish workers in 12 plants in each country found that only $39 \%$ of the Japanese to be satisfied with their jobs as contrasted with $70 \%$ of the British and 83\% of the Swedish workers (see Azumi and McMillan, 1976). Additional comparisons of Japanese and American workers by Pascale and Mcguire (1980) and Naoi and Schooler (1985) also show that Japanese are significantly less 
satisfied with their jobs. Harrison (1995) observes that Singaporean managers report a lower level of satisfaction with their jobs than did their Australian counterparts. This was predicted from the cultural characteristics of Singaporean society as compared with Australia. Between-cultures studies of job satisfaction have generally found that collectivists have lower levels of job satisfaction than the individualists (Lincoln, 1989). One study (Hui, Yee, and Eastman, 1995) has found job satisfaction to be higher for collectivist employees, but it should be noted that the study was a within-culture and not a cross-cultural one. In her study Fauziah (2000) found that Australian managers (individualist culture) appear to have a significantly higher level of job satisfaction than their counterpart in Malaysia (collectivist culture). Fauziah and Anizah (2003) found that Malaysians who are reportedly as having a collectivist culture (Hofstede, $1980 ; 1984)$ have moderate level of job satisfaction. Hence, the findings on this area are still inconclusive. In seeking answers to this contradictory finding on general satisfaction, this study assessed the means on individual items of the general satisfaction measure with the intention of identifying the significance of each item (Table 1).

The individual means of each statement in the measure indicate that the only statement that has a mean of greater than 4.00 is statement \#3: "All in all, how satisfied are you with your job." This clearly indicates that the respondents are highly satisfied with their job but the same does not hold true for the other statements in the measure which only indicate a moderate level of satisfaction. Therefore, the findings on general satisfaction of this study are not consistent with findings in the literature. To determine whether the perceived differences between means in relations to general satisfaction based on gender and country of education of the respondents were significant or not, two sets of t-test were conducted. General satisfaction showed no indication of significant differences between genders. Similarly, general satisfaction showed no significant differences on whether the respondents had their education in the Asian or Western countries.

Overall, there is no significant differences between male and female respondents with regard to general satisfaction (Table 2). In other word, general satisfaction does not increase as a function of gender.

Overall, there are no significant differences between male and female respondents with regard to general satisfaction. In other word, general satisfaction does not increase as a function of gender. Nevertheless, a detailed t-test conducted on the individual statements of the measure indicate that the male respondents have a significantly higher level of general satisfaction than their female counterparts in terms of their satisfaction towards the university compared to other organisations. In addition, the male respondents (Table 3) felt satisfied with their chances for getting ahead in the university in the future $(\mathrm{p}=.02)$.

Similar to t-test on gender, overall, there are no significant differences between Asian and Western educated respondents with regard to general satisfaction. In other word, general satisfaction does not increase as a function of country of education. In addition, a detailed t-test conducted on the individual statements of the measure indicates that "country of education" have no significant impact on the respondents' perception toward general satisfaction as indicated in Table 4. No significant differences were detected in any one of the statements of the measure (Tables 2,3 and 4).

The One-way between Groups ANOVA with Post-hoc Comparisons results for general satisfaction (see Table 5) indicate that there are significant differences between the levels of general satisfaction between respondents in the age category. The academic staff in the Associate Professor group indicates a significantly higher level of job satisfaction than their Senior Lecturer counterparts. It appears that those academic staff who were in the $>44$ years of age experience a significantly higher level of general satisfaction than those in the $31-44$ age group. In addition, those in the "Never married" category and in the "Married" category show a significantly higher level of general satisfaction than those in the divorced group. Finally, respondents whose annual basic salary is "> RM54, 000" have significantly higher level of general satisfaction than those in the "RM34,000 - RM38,000" salary brackets (Table 5).

Mathieu and Hammel (1989) and Bateman and Strasser (1984) have shown that older employees tend to be more satisfied and more committed to the organisation due to adjustment and investment processes. Mannheim, Baruch, and Tal (1997) found age to be positively related to job satisfaction. Evidently, for the type of highly educated personnel in their sample, no disengagement processes related to aging are indicated by general satisfaction (see also Mannheim and Reiss, 1981) - the older age group remains highly committed to its work role and organisation, and is highly satisfied. Griffin and Bateman (1986) report a positive relationships between job satisfaction and age, income, and occupation in a national sample whereas demographic variables such as gender and race seem to play little role in job satisfaction. The results in present study support the existing findings mentioned above. Therefore, current position, age, marital status, and salary appear to be the factors that influence general satisfaction for the respondents at the individual level analysis.

Based on the findings of previous research on organisational climate, universities that conduct organisational climate surveys may experience one or more of the following benefits 
- Employee Job Satisfaction. A positive and healthy university climate translates into increased academic staff job satisfaction and productivity.

- Employee Involvement. By administering an organisational survey, academic staff are given the opportunity to be involved in the university at different level that is typically defined in their job descriptions. Research has shown that employees who are more involved in the organisation may also be more satisfied with the job, miss fewer days of work, stay with an organisation longer, and perform better on the job.

- Positive Work Outcomes. To date, a significant amount of evidence in the literature has been accumulated documenting the importance of the work environment in relation to organisational performance. In general, research has shown that factors in the work environment are related to outcomes such as employee motivation, job satisfaction, intentions to quit, job performance, and even organisational productivity. In addition, the emerging area of research has indicated that organisational climate can influence customer perceptions of the quality of products or services delivered by an organisation.

- Communication Forum. In many large universities it can be very difficult to communicate with the majority of academic staff. The management of the universities may only have limited amounts of time to talk to the academic staff about day-to-day activities. Conversations regarding an academic staff's work environment can fall to the wayside, and in some instances, never take place. Organisational climate surveys that occur on a scheduled basis (e.g., annually, biannually, etc.) can be a more efficient way for the management to gather important information.

- Industry Comparison. Universities often look at other universities when determining university policies and procedures. It is quite common for universities (especially in developed countries) to "explore the market" or conduct "benchmark" studies when considering issues such as marketing strategies, new academic programs, etc. A common question asked is "How do we compare to others?" One advantage of conducting an organisational climate survey is that it can provide an opportunity to compare the university's work environment to that of other universities.

- Proactive Management. Administering organisational climate surveys allow the management of the university to be more proactive in managing the academic staff and work environments. When used on a scheduled basis, organisational climate surveys can help pinpoint problems areas within the work environment before they grow into a crisis needing immediate attention. Problems that require a reactive posture interrupt the normal workflow, and typical cause delays in providing products or services to customers.

For many universities, the proper implementation of an organisational climate survey can provide valuable information that can be use to guide and increase its success. However, universities that choose to implement a survey must be prepared to respond to both positive and negative results, and work with employees, in this case, the academic staff, to make improvements in the work environment. Failure to respond to employee feedback can ultimately increase the number of workforce problems experienced within a university and this can lead to negative repercussion to the university concerned. To be a world class university, the university needs to have world class academic staffs that are dedicated, competent, knowledgeable, and above all committed to the university and their career. But, all these attributes may eventually diminish if these academic staff perceived that they are not experiencing job satisfaction at the university. Hence, it is strongly recommended that the university should consider conducting a university-wide organisational climate survey because the data gathered can provide valuable information that can be use to guide and increase its success in achieving a world class university in the future.

\section{Conclusion}

Overall, the findings of the present study have provided answers to the research questions. The findings suggest that the academic staff of the university have a moderate level of general satisfaction. The demographic variables that is, current position, age, marital status, and salary appear to represent antecedent conditions of the general satisfaction. These findings have practical implications for the management of the university. Academic staffs that have different levels of job satisfaction may require different management styles and motivational strategies for optimum organizational effectiveness. At the same time the management of the university needs probe into the causes of low general satisfaction among its academic staff. This is of prime importance because research findings have consistently found that job satisfaction has significant impact on employee commitment to the organizations, job performance, and motivation. At the same time employees with high job satisfaction would lead to lower turnover and absenteeism. One way in which the management of the university can identify the factors that cause low job satisfaction is by using Organisational Climate Survey. Organisational climate can be described as a combination of shared history, expectations, unwritten rules and social mores that affects the behaviour of everyone in an organisation. Or, more simply, it is a set of underlying beliefs that are always there to colour the perceptions of actions and communications. Organisational climate assessments are accepted today as a vital component in helping organisations determine employee perceptions and feelings about their work groups, leadership, work environment, decision-making, job satisfaction, etc. of departments / faculties and the university at large. The most important purpose of the survey, though, is not just to 
gather the data but to use the data to identify opportunities for improvement and, ultimately, to help evaluate the effectiveness of changes already implemented.

Several limitations exist in the present study which warrants review. First, the results of this study must be qualified in terms of the samples that were used. Extensive sampling was beyond the resources of the researcher. To enhance external validity, future research efforts should obtain a representative sample from several universities, ideally using longitudinal research design to establish causal relationships among the variables. Second, since only academic staff was used as samples in this study, this raises the issue of generalisability of findings. More research is needed before firm generalisable implications for academic staff can be drawn. Generalisability of the results of these analyses for non-academic staff remains an open empirical question. Additional replication using a more careful comparison by types of employees and types of occupation would be useful. Finally, a possible limitation of the study is some method bias resulting from the use of a common instrument (questionnaire). However, this is unlikely to be a serious problem because Spector (1987) has shown that method bias is generally not a problem with well-developed instruments. The high alpha levels are evidence of the soundness of the instruments in the present study. Nevertheless, future research should combine the use of questionnaire method with observation, and field experimentation. In addition, longitudinal investigation could be conducted to determine whether variable effects change over time.

\section{References}

Azumi, K. and McMillan, C. J. (1976). Worker sentiment in the Japanese factory: Its organizational determinants. In L. Austin (ed.), Japan: The paradox of progress (pp. 215-229). New Haven: Yale University.

Borg, M. and Riding, R. G. (1991). Educational Psychology, (11), 1, 59-171.

Cole, R. E. (1979). Work, mobility, and participation. Berkeley: University of California.

de Boer, C. (1978). The polls: Attitudes toward work. Public Opinion Quarterly, 42, 414-423.

Fauziah Noordin. (2000). Individualism-Collectivism and Organisational Commitment: A Comparative Study between Australian and Malaysian Managers. Unpublished Report Universiti Teknologi MARA, Malaysia.

Fauziah Noordin and Anizah Zainuddin. (2003). Affective, continuance, and normative commitment of academic staff: a case of a public university in Malaysia. Unpublished Report Universiti Teknologi MARA, Malaysia

Fresko, B. Kfir, D, and Nasser, F. (1997). Predicting teacher commitment. Teaching and Teacher Education, 13(4), 429-438.

Griffeth, R. W., \& Hom, P. W. (1987). Some multivariate comparisons of multinational managers. Multivariate Behavioral Research, 22, 173-191.

Harrison, G. L. (1995). Satisfaction, tension and interpersonal relations: A cross-cultural comparison of managers in Singapore and Australia. Journal of Managerial Psychology, 10, 13-19.

Hofstede, G. (1980). Culture's consequences. Beverly Hills, CA: Sage Publications.

Hofstede, G. (1984). Culture's consequences: International differences in work-related values. Beverly Hills, CA: Sage.

Hui, C. H., Yee, C., \& Eastman, K. L. (1995). The relationship between individualism-collectivism and job satisfaction. Applied Psychology: An International Review, 44, 276-282.

Koch, J. and Steers, R. (1978). Job attachment, satisfaction, and turnover among public employees. Journal of Vocational Behavior, 12, 119-128.

Levin, I. And Stokes, J. P. (1989). Dispositional approach to job satisfaction: Role of negative affectivity. Journal of Applied Psychology, 74, 752-758.

Lincoln, J. R. (1989). Employee work attitudes and management practices in the US and Japan: Evidence from a large comparative survey. California Management Review, 32, 89-106.

Locke, E. A. (1976). The nature and causes of job satisfaction. In M. D. Dunnette (ed.), Handbook of industrial and organizational psychology (pp. 1297-1349). Chicago: Rand McNall.

Naoi, A. and Schooler, C. (1985). Occupational conditions and psychological functioning in Japan. American Journal of Sociology, 90, 729-751.

Nunnaly, J. C. (1967). Psychometric theory. New York: McGraw-Hill.

Odom, R. Y., Boxx, W. R., and Dunn, M. G. (1990). Organizational cultures, commitment, satisfaction, and cohesion. Public Productivity Management Review, 14, 157-168.

Pascale, R. T. and Mcguire, M. A. (1980). Comparison of selected work factors in Japan and the United states. Human Relations, 33, 433-455. 
Rosin, H. M., \& Korabik, K. (1991). Workplace variables, affective responses, and intention to leave among women managers. Journal of Occupational Psychology, 64, 317-330.

Sing, K. and Billingsley, B. S. (1998). Professional support and its effects on teachers' commitment. Journal of Educational Research, 1(4), 229-239.

Spector, P. E. (1982). Behaviour in organisations as a function of employee's locus of control. Psychological Bulletin, 91, 482-497.

Taylor, J. C., \& Bowers, D. G. (1972). Survey of organisations. Ann Arbor: University of Michigan.

Testa, M. R. (2001). Organizational commitment, job satisfaction, and effort in the service environment. The journal of Psychology, 135, 256-266.

Welsh, H. P. and La Van, H. (1981). Interrelationships between organizational commitment and job characteristics, job satisfaction, professional behavior, and organizational climate. Human Relations, 34, 1079-1089.

Table 1. Individual Means of the Measures

\begin{tabular}{|c|c|}
\hline Items & Means \\
\hline 1. All in all, how satisfied are you with the persons in your work group? & 3.86 \\
\hline 2. All in all, how satisfied are you with your immediate superior? & 3.84 \\
\hline 3. All in all, how satisfied are you with your job? & 4.26 \\
\hline 4. All in all, how satisfied are you with this organisation, compared to most others? & 3.93 \\
\hline $\begin{array}{l}\text { Considering your skills and the effort you put into your work, how satisfied are you } \\
\text { with your pay? }\end{array}$ & 3.57 \\
\hline $\begin{array}{l}\text { 6. How satisfied do you feel with the progress you have made in this organisation } \\
\text { up to now? }\end{array}$ & 3.80 \\
\hline $\begin{array}{l}\text { 7. How satisfied do you feel with your chances for getting ahead in this } \\
\text { organisation in the future? }\end{array}$ & 3.44 \\
\hline Total Mean & 3.82 \\
\hline
\end{tabular}

Table 2. Independent Groups T-Tests

\begin{tabular}{|l|c|c|c|c|}
\hline \multicolumn{1}{|c|}{ Variables } & Mean & Std. Dev. & T-Value & 2-tail sig. \\
\hline Gender & & & & \\
Female & & & -1.711 & .088 \\
Male & 3.7622 & .6086 & & \\
& 3.8970 & .6334 & & .764 \\
Country of Education & & & .301 & \\
Asian & 3.8195 & .6001 & & \\
Western & 3.7955 & .6440 & & \\
\hline
\end{tabular}

Table 3. Individual Means of the Measures (Gender)

\begin{tabular}{|c|c|c|c|c|}
\hline Items & $\begin{array}{c}\text { Means } \\
\text { (Female) }\end{array}$ & $\begin{array}{l}\text { Means } \\
\text { (Male) }\end{array}$ & T-Test & Sig. \\
\hline $\begin{array}{l}\text { 1. All in all, how satisfied are you with the persons in your work } \\
\text { group? }\end{array}$ & 3.83 & 3.91 & -.772 & .441 \\
\hline 2. All in all, how satisfied are you with your immediate superior? & 3.84 & 3.82 & .198 & .843 \\
\hline 3. All in all, how satisfied are you with yourjob? & 4.27 & 4.25 & .274 & .784 \\
\hline $\begin{array}{l}\text { 4. All in all, how satisfied are you with this organisation, } \\
\text { compared to most others? }\end{array}$ & 3.84 & 4.07 & -2.180 & .030 \\
\hline $\begin{array}{l}\text { 5. Considering your skills and the effort you put into your work, } \\
\text { how satisfied are you with your pay? }\end{array}$ & 3.45 & 3.74 & -1.899 & .059 \\
\hline $\begin{array}{l}\text { 6. How satisfied do you feel with the progress you have made in } \\
\text { this organisation up to now? }\end{array}$ & 3.75 & 3.90 & -1.295 & .197 \\
\hline $\begin{array}{l}\text { 7. How satisfied do you feel with your chances for getting ahead } \\
\text { in this organisation in the future? }\end{array}$ & 3.32 & 3.60 & -2.190 & .029 \\
\hline
\end{tabular}


Table 4. Individual Means of the Measures (Country of Education)

\begin{tabular}{|c|c|c|c|c|}
\hline Items & $\begin{array}{l}\text { Means } \\
\text { (Asian) } \\
\end{array}$ & $\begin{array}{c}\text { Means } \\
\text { (Western) } \\
\end{array}$ & T-Test & Sig. \\
\hline $\begin{array}{l}\text { 1. All in all, how satisfied are you with the persons in your work } \\
\text { group? }\end{array}$ & 392 & 3.78 & 1.296 & .193 \\
\hline 2. All in all, how satisfied are you with your immediate & 3.97 & 3.69 & 2.296 & .023 \\
\hline superior? & 4.21 & 4.27 & -.763 & .446 \\
\hline 3. All in all, how satisfied are you with your job? & 3.99 & 3.86 & 1.233 & .219 \\
\hline $\begin{array}{l}\text { 4. All in all, how satistied are you with this organisation, } \\
\text { compared to most others? }\end{array}$ & 3.44 & 3.66 & -1.421 & .157 \\
\hline $\begin{array}{l}\text { 5. Considering your skills and the effort you put into your work, } \\
\text { how satisfied are you with your pay? }\end{array}$ & 3.74 & 3.85 & -.957 & .339 \\
\hline $\begin{array}{l}\text { 6. How satisfied do you feel with the progress you have made in } \\
\text { this organisation up to now? }\end{array}$ & 3.48 & 3.41 & .497 & 620 \\
\hline $\begin{array}{l}\text { 7. How satisfied do you feel with your chances for getting ahead } \\
\text { in this organisation in the future? }\end{array}$ & & & & \\
\hline
\end{tabular}

Table 5. One-Way between Groups ANOVA with Post-Hoc Comparison

\begin{tabular}{|c|c|c|c|c|}
\hline Variables & Mean & Std. Dev. & F-ratio & F-probability \\
\hline $\begin{array}{l}\text { Current position } \\
\text { Junior Lecturer } \\
\text { Senior lecturer } \\
\text { Lecturer DM53 } \\
\text { Associate Professor } \\
\text { Professor } \\
\text { Other }\end{array}$ & $\begin{array}{l}3.8912 \\
3.6502^{\mathrm{a}} \\
4.0195 \\
3.9474^{\mathrm{b}} \\
4.2500 \\
4.1964\end{array}$ & $\begin{array}{l}.6301 \\
.5268 \\
.7030 \\
.7307 \\
.5393] \\
.4826\end{array}$ & 4.06 & .001 \\
\hline $\begin{array}{l}\text { Marital status } \\
\text { Never married } \\
\text { Married } \\
\text { Divorced } \\
\text { Separated } \\
\text { Widowed }\end{array}$ & $\begin{array}{c}3.8519^{\mathrm{aa}} \\
3.8202^{\mathrm{aa}} \\
2.5714^{\mathrm{bbb}} \\
- \\
-\end{array}$ & $\begin{array}{c}.5128 \\
.6282 \\
.0000 \\
- \\
-\end{array}$ & 4.128 & .017 \\
\hline $\begin{array}{l}\text { Age Group } \\
<31 \text { years } \\
31-44 \text { years } \\
>44 \text { years }\end{array}$ & $\begin{array}{l}3.7823 \\
3.7280^{\mathrm{a}} \\
4.0398^{\mathrm{b}}\end{array}$ & $\begin{array}{l}.5329 \\
.5954 \\
.7014\end{array}$ & 5.625 & .004 \\
\hline $\begin{array}{l}\text { Annual basic salary } \\
<\text { RM24,000 } \\
\text { RM24,000 - RM28.000 } \\
\text { RM29.000 - RM33,000 } \\
\text { RM34,000 - RM38,000 } \\
\text { RM39,000 - RM43,000 } \\
\text { RM44,000 - RM48,000 } \\
\text { RM49,000 - RM53,000 } \\
>54,000\end{array}$ & $\begin{array}{c}3.8929 \\
3.8278 \\
3.6316 \\
3.5775^{\mathrm{a}} \\
3.8214 \\
3.7302 \\
3.7640 \\
4.0612^{\mathrm{b}}\end{array}$ & $\begin{array}{l}.6826 \\
.6646 \\
.4320 \\
.5125 \\
.5071 \\
.4793 \\
.5773 \\
.7440\end{array}$ & 2.845 & .007 \\
\hline
\end{tabular}

Note: Those with different superscripts differ significantly $(\mathrm{P}<.05)$. Those that share a superscript, or for which no superscripts appear, are not significantly different from each other $(\mathrm{p} \geq .05)$. 